This item was submitted to Loughborough's Research Repository by the author.

Items in Figshare are protected by copyright, with all rights reserved, unless otherwise indicated.

\title{
An availability approach to thermal energy recovery in vehicles
}

PLEASE CITE THE PUBLISHED VERSION

PUBLISHER

Professional Engineering Publishing / @ IMechE

VERSION

VoR (Version of Record)

LICENCE

CC BY-NC-ND 4.0

REPOSITORY RECORD

Stobart, Richard. 2009. "An Availability Approach to Thermal Energy Recovery in Vehicles". figshare. https://hdl.handle.net/2134/4780. 
This item was submitted to Loughborough's Institutional Repository (https://dspace.lboro.ac.uk/) by the author and is made available under the following Creative Commons Licence conditions.

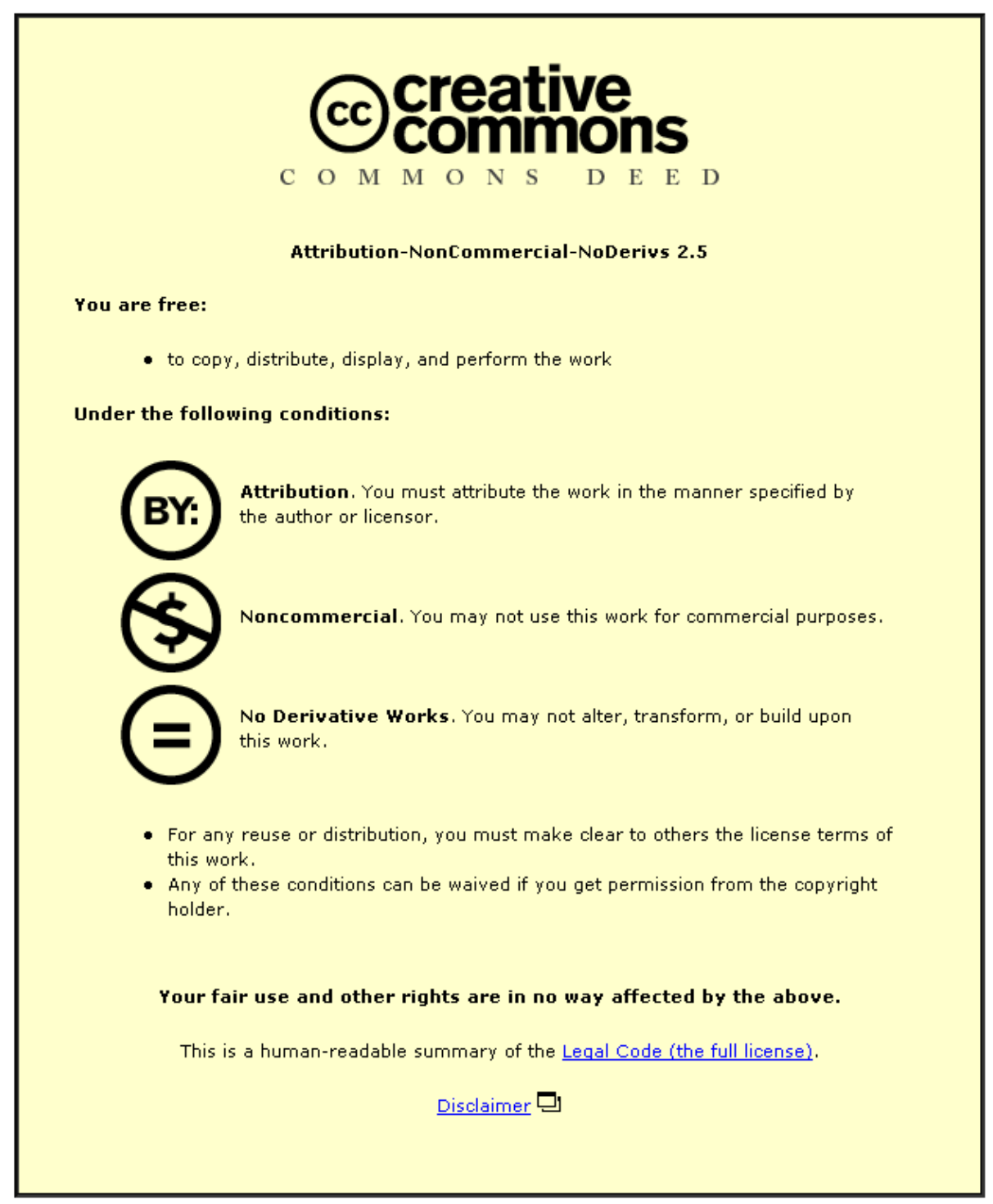

For the full text of this licence, please go to: http://creativecommons.org/licenses/by-nc-nd/2.5/ 


\title{
An availability approach to thermal energy recovery in vehicles
}

\author{
R K Stobart \\ Department of Aeronautical and Automotive Engineering, Loughborough University, Loughborough, Leicestershire, \\ LE11 3TU, UK. email: r.k.stobart@lboro.ac.uk
}

The manuscript was received on 14 October 2006 and was accepted after revision for publication on 19 April 2007.

DOI: 10.1243/09544070JAUTO463

\begin{abstract}
Availability is a well-established and widely recognized way of describing the work-producing potential of energy systems. A first-law analysis is helpful in setting the energy context and ensuring that energy flows balance, but it is a second-law analysis based on availability that places an upper bound on the potential work output. In this analysis a new approach to thermal management intended for vehicle propulsion is examined and developed. Starting with a simple analysis of the chemical energy flow, a realistic heat exchange performance is introduced to establish a practical architecture. Within this framework, the availability analysis shows that effective thermal efficiencies of between 25 and 30 per cent are feasible. With a spark ignition engine operating at a high load condition, and the thermal recovery system at an operating pressure of 100 bar, the maximum efficiency possible with a steady flow work-producing device is 37 per cent (with fully reversible thermodynamic processes). In a water-based thermal recovery system, work could only reasonably be produced with heat transfer from a reservoir at the saturation temperature corresponding to the operating pressure. At 100 bar the maximum efficiency would be 33 per cent. In a different mode of operation, where heat is transferred incrementally to a thermal accumulator and work produced as required, the efficiency is 32 per cent at only 20 bar operating pressure. These efficiency values apply to work production to supplement a combustion engine at any operating condition. An analysis of a reciprocating expander as the work-producing device shows substantial flexibility in operation. Control of system operating pressure is shown to be of value in that periodic adjustments enhance the availability content of the thermal reservoir. The operating pressure of a fluid power system is related to the temperature of operation, and therefore the heat transfer processes. Choice of too high a pressure leads to reduced heat transfer, and ultimately a reduction in work output. There is an optimum condition that can be selected at design time and maintained during the running of the system.
\end{abstract}

Keywords: thermal energy recovery, fuel economy, availability, hybrid vehicles, heat transfer, steam, thermodynamic cycles

\section{INTRODUCTION}

Internal combustion engines operate on the principle that a substantial heat release in a working fluid can be harnessed and can be converted to shaft work through a controlled expansion. Since the conversion of energy to work is the consequence of a heat release, the efficiency of an engine is usually related to the heating potential or calorific value of the fuel.

The use of thermal efficiency, while convenient, is not a true measure of the ability of the engine to use the fuel for work production. The shaft work that can be recovered in a fully reversible process is equal to the change in Gibbs free energy as opposed to the lower calorific value (LCV) of the fuel [1]. The criterion by which a heat engine is judged is therefore the rational efficiency defined as

$$
\eta_{\mathrm{r}}=-\frac{W}{\Delta g_{0}}
$$

compared with the thermal efficiency based on the LCV, $\Delta h_{0}$

$$
\eta_{\mathrm{th}}=-\frac{W}{\Delta h_{0}}
$$


where, in each case, $W$ is the work produced per unit mass of fuel consumed.

A comparison with rational efficiency helps measure the success in converting the available energy to useful work. The available energy, expressed as the difference between exergy flows into and out of a work-producing device, is the maximum work that can be produced from those flows.

For hydrocarbon fuels, $\Delta h_{0} \approx \Delta g_{0}$, so that the two forms of efficiency can be used interchangeably with the kind of fuels used in current-production internal combustion (IC) engines.

The failure of practical engines to approach a high rational efficiency is due to a range of irreversible processes. Within the cylinder, expansion of gases is rapid, with consequent large temperature differences, fluid motion, and heat transfer to the cylinder walls and piston crown. In order for the cylinder to be prepared for successive cylinder events, the still expanding exhaust gases must be released while their pressure exceeds atmospheric, and consequently there is significant heat transfer simply through the movement of hot exhaust gases through the exhaust manifold. It is therefore a consequence of the fundamental design of the engine. Such a hot stream of gas offers potential for energy recovery in the form of shaft work that will supplement the work output of the engine.

In modern diesel engines, energy is recovered from the exhaust gas flow by means of a turbocharger. The resulting compressed air does work on the piston during induction to supplement the combustion work. Other methods of energy recovery are possible, and the approach described in this paper utilizes energy storage in the form of saturated, pressurized water.

The purpose of this paper is firstly to describe the work production potential of a thermal recovery system for an IC engine propelled vehicle. The system described uses a water-based fluid power cycle where energy is stored in a saturated water reservoir in contact with a small quantity of steam at the system working pressure. The steam is expanded through a small reciprocating device that forms part of a closed-loop system. Since the system is additional to the main systems of the car, its efficiency is of great interest. Heat transfer can be achieved using perhaps heavy and costly heat exchange equipment. To make this additional mass worthwhile, an understanding of efficiency and how a high efficiency can be achieved is essential. The argument presented in this paper begins with an understanding of the available energy at a nominal operating condition and in various hardware configurations. From that presentation, it is argued that efficiency and heat transfer can be balanced to maximize work production, but high efficiency requires optimization and control of the complete system. In later sections, principles of system operation are discussed that reduce irreversibilities.

\section{THERMAL ENERGY RECOVERY FROM HEAT ENGINES}

There is a long history of attempts to create efficient engine systems by supplementing the shaft work with work produced by a thermal recovery system. One of the best documented is the Still engine, an invention of W. J. Still that first saw marine application in the early twentieth century [2]. The Still engine was a heavily integrated device. Power was produced from double-acting cylinders, with a diesel cycle acting on the upper surface of the piston and steam acting on the lower surface. Steam was raised by firstly heating water in the cooling jacket of the engine. The hot water passed through a boiler heated by engine exhaust gases.

Numerous tests were conducted on the Still engine. Comparative tests reported in 1920 showed that the Still engine had up to 3 percentage points advantage over a Sulzer diesel engine of comparable size. In 1927 a locomotive was built by Messrs Kitson \& Company of Leeds, UK, that incorporated the Still engine. The locomotive saw service in the Leeds area. It demonstrated a substantial improvement in thermal efficiency over steam locomotives (14 per cent over 8 per cent drawbar efficiency), but did not compare well with emerging diesel engines. On the test bed the Still engine was able to return a fuel consumption of $210 \mathrm{~g} / \mathrm{bkW} \mathrm{h}$, but this proved impossible to realize on the locomotive. This early attempt to implement a high-efficiency system while showing thermodynamic promise failed as a practical and reliable system. Control systems were rudimentary, and there was no attempt to find optimal operating conditions. An important aspect of the design, that of enhancing heat transfer from cylinders to the cooling jacket of the engine, may have been poorly conceived. This process of transferring high-grade energy from the engine cylinder would almost certainly have produced a loss of available energy.

Modern spark ignition engines used in vehicle applications achieve thermal efficiencies of between 25 and 30 per cent. Heat is rejected both to coolant and through the exhaust flow in roughly equal proportion. This proportion can be changed, for example, through choice of the engine calibrations. 
Early exhaust valve opening will, for example, tend to change the balance through the reduced exposure of cylinder surfaces to hot gas, resulting in greater heat transfer to exhaust.

With a growing interest in vehicle fuel economy there has been a revival of investigations into thermal energy recovery techniques. Reference [3] is a modelling study supported by some experimental data based on a Rankine cycle that is designed to supplement the charging current to the battery of a hybrid vehicle. The authors report success with a combined (block and exhaust) heat transfer scheme. The heat exchange process in the exhaust imposes a high back pressure on the engine, leading to losses that counteract the efficiency gains. The total energy recovery is $8 \mathrm{~kW}$ or about 10 per cent of the total waste heat. Reference [4] gives an example of the application of a Rankine cycle to recover thermal energy in a hybrid vehicle. The authors report the use of a small turbine as the expansion device.

The system that is the subject of analysis in this paper utilizes a heat exchanger and pressurized accumulator to store water at saturated conditions and an elevated pressure. Heat transfer from the exhaust gases causes, over a period, an increase in pressure and temperature of the stored water up to a working pressure that, according to application, will lie between 20 and 100 bar. The system is illustrated in Fig. 1 (adapted from reference [5]). The system design is still largely conceptual, although there is now a proposed heat exchange design that is the source of data for the analysis presented here. The figure shows a control system concept in which the engine load is managed through fuel flow while the energy recovery process is managed through maintenance of flowrate and pressure in the water-steam system. Other control concepts are feasible and will be explored in future publications.

As energy is available, water is released from the accumulator and is subject to a small pressure drop. It is converted to steam in a slightly superheated state. The steam is then expanded through a multiplestage expander, and useful work is extracted. The steam is then condensed and, in the form of water, is repressurized and circulated to the heat exchange system. Significant superheat is not considered in this analysis principally because of the mechanical complexity that would make such a system impractical in a vehicle application. The shaft work produced by the system could be used in a number of ways. It could be applied directly to the mechanical propulsion system of the vehicle or connected through a generator to produce electricity to supplement either propulsion power in a hybrid vehicle or to support the electrical loads.

\section{BASIC IDEAS OF AVAILABILITY}

The notions of availability are well established and developed (see reference [1] for definitions and references [6] and [7] for examples of their application). The specific steady flow availability, $b$, may be used to predict the reversible work output in steady flow between two states, 1 and 2, as

$$
W_{\mathrm{rev}}=b_{1}-b_{2}
$$

where $b$ is defined as $b \equiv h-T_{0} s$ and is a state of the fluid.

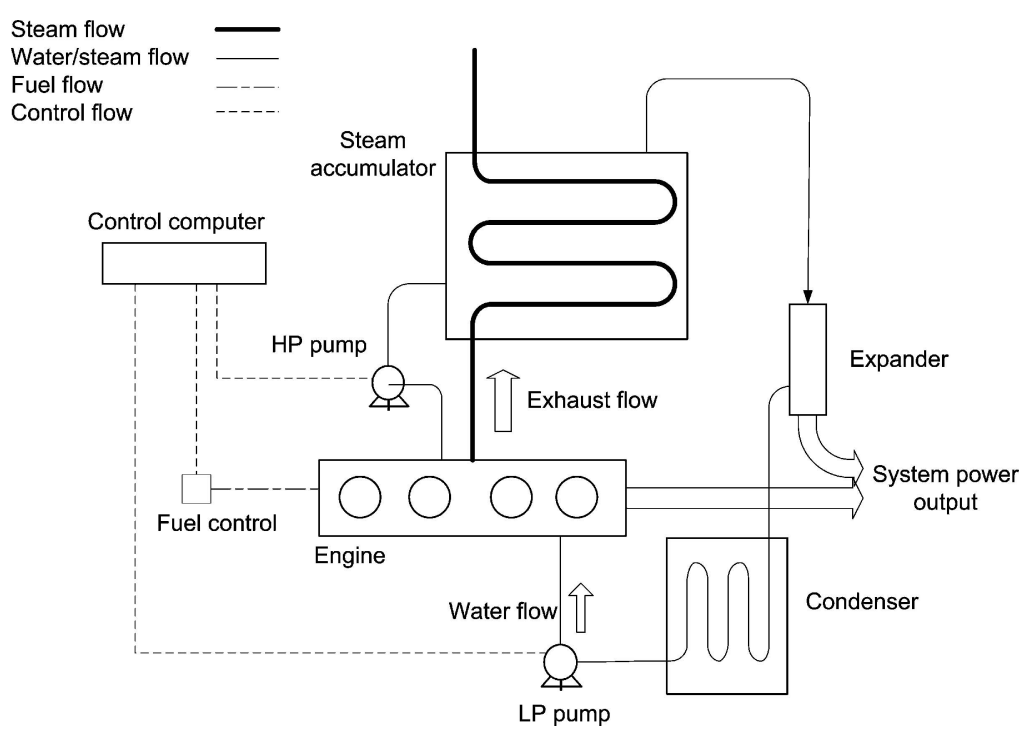

Fig. 1 System schematic 
The schematic of energy flow in Fig. 2 shows a steady flow of gas from the engine through an exhaust system, where heat is rejected to a work-producing device and from which useful shaft work is extracted. Heat is rejected to a lower temperature reservoir. In practice, heat is rejected to the environment through a multiplicity of paths, and it is safe to assume that heat is finally rejected to the environment at $T_{0}$. No work is produced during the passage of the gas through the exhaust system. However, a workproducing device could be added that uses the exhaust gas as a heat source (with the environment at $T_{0}$ as a sink).

The heat rejected, $Q_{\text {in,work }}$, is $Q_{\text {in }}-Q_{\text {out }}$. With a mass flow of $\dot{m}$, the heat rejected may also be expressed as $Q_{\text {in,work }}=\dot{m}\left(h_{2}-h_{1}\right)$. Since heat is rejected reversibly at a temperature $T$ to a work-producing device and then rejected to the environment at $T_{0}$, the reversible heat transfer to the device may also be expressed as $T\left(s_{2}-s_{1}\right)$.

A fully reversible plant with heat transfer from $T$ to $T_{0}$ operates at a thermal efficiency of

$$
\eta_{\mathrm{th}}=1-\frac{T_{0}}{T}
$$

The maximum possible useful work is therefore

$$
\begin{aligned}
\eta_{\mathrm{th}} T\left(s_{2}-s_{1}\right) & =\left(1-\frac{T_{0}}{T}\right) T\left(s_{2}-s_{1}\right) \\
& =h_{2}-h_{1}-T_{0}\left(s_{2}-s_{1}\right)=b_{2}-b_{1}
\end{aligned}
$$

\section{APPLICATION OF AVAILABILITY ANALYSIS TO ENERGY RECOVERY FROM INTERNAL COMBUSTION ENGINES}

The efficiency of the thermal recovery system is of fundamental importance. Once a system design that maximizes heat transfer has been developed, its value

\section{Exhaust System}

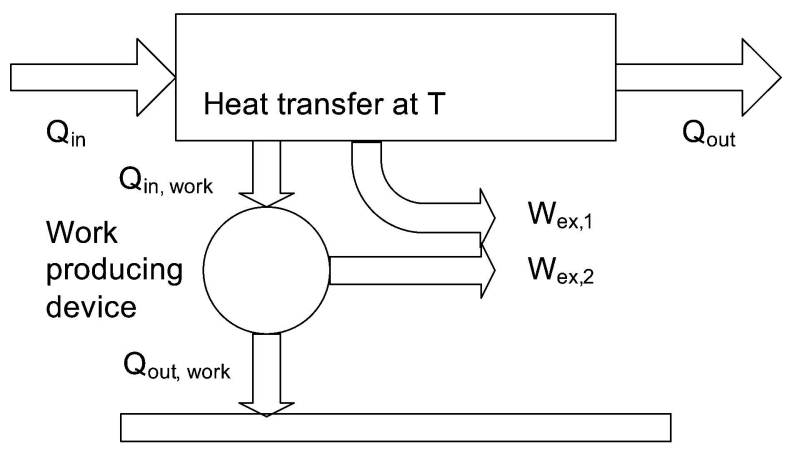

Environment, $\mathrm{T}_{0}$

Fig. 2 System energy flows can only be realized by high-efficiency conversion to work. The analysis of the energy recovery system (illustrated in Fig. 1) follows a series of steps to identify firstly the maximum possible work that could be produced by an internal combustion engine and by implication the thermal efficiency. By imposing a succession of practical constraints, an estimate for the work output from an energy recovery system is developed. These steps are phrased as questions.

1. If the engine were able to work at 100 per cent rational efficiency, what would the work output be? (see section 4.1.)

2. If the engine were to work at realistic conditions, but the energy recovery from the exhaust gas were to be fully reversible, what would the work output be? (see section 4.2.)

3. If the heat transfer from the exhaust can only be made between the exhaust flow and saturated water at a given pressure, what is the work output? (see section 4.4.)

4. Finally, if the heat transfer is made to charge a reservoir and increase the energy content of the working fluid from which fluid is discharged and expanded to make useful work, what is the thermal efficiency? (see sections 4.5 and 4.6.)

The basic data for the analysis are taken at a single operating condition of a spark ignition engine operating at $72 \mathrm{~kW}$ output power in which $0.1 \mathrm{~kg} / \mathrm{s}$ of exhaust gas is passing through the exhaust system where its temperature drops from 511 to $163^{\circ} \mathrm{C}$. The engine is operating at stoichiometric conditions with a brake specific fuel consumption of $300 \mathrm{~g} /$ bkW h. For the fuel, $\Delta h_{0}$ is $44.43 \mathrm{MJ} / \mathrm{kg}$. The system operating pressure is $100 \mathrm{bar}$, corresponding to a water saturation temperature of $311^{\circ} \mathrm{C}$.

The reason for choosing this point was that the research team had an independently validated heat transfer calculation at this condition. The rationale for using this result as the basis for the subsequent analysis has several aspects.

1. The engine output at $72 \mathrm{~kW}$ is high for the road load of a passenger car; the exhaust temperature values are nevertheless typical. Measurements conducted at Sussex on a 1.1 L naturally aspirated direct-injection spark-ignition (DISI) engine at $60 \mathrm{rev} / \mathrm{s}$ and 4 bar b.m.e.p. (typical road load condition) confirmed an exhaust temperature of $622^{\circ} \mathrm{C}$. The thermodynamic calculations all scale linearly with mass flow given similar inlet exhaust temperature conditions.

2. The chosen power and corresponding flowrates are representative of the road load conditions of 
a larger vehicle such as a freight vehicle with a medium-speed diesel engine. Further measurements at Sussex on a 7.2 L boosted diesel engine indicated an exhaust temperature of $527^{\circ} \mathrm{C}$ at $30 \mathrm{rev} / \mathrm{s}$ and 6 bar b.m.e.p., corresponding to an output power of $62 \mathrm{~kW}$.

At lower exhaust temperatures, the available energy in the exhaust gas from the engine diminishes. This aspect of system operation is discussed later in the paper. However, the nature of the energy recovery system discussed in the paper is that thermal energy is stored and tends to isolate the heat transfer processes from the later recovery of energy. Reference [8] includes a description of drive cycle calculations that use the heat transfer parameters discussed in this paper to estimate cycle fuel consumption for a ' $\mathrm{C}$ ' segment passenger car equipped with a spark ignition engine and the energy recovery system discussed in this paper.

\subsection{Ideal work output from an engine consuming a chemical fuel}

The ideal work output per unit mass of fuel is simply the change in Gibbs function between inlet and exhaust conditions. The present example is based on a single operating point of a gasoline (spark ignition) engine with a $72 \mathrm{~kW}$ brake output, an exhaust flowrate of $0.1 \mathrm{~kg} / \mathrm{s}$, and a fuel flow based on stoichiometric conditions of $0.006 \mathrm{~kg} / \mathrm{s}$. The value of $\Delta g_{0.298}=-45.79 \mathrm{MJ} / \mathrm{kg}$ for a gasoline fuel implies a maximum work output of $275 \mathrm{~kW}$ if the exhaust gases are cooled to the temperature of the environment. The lost work with the exhaust conditions at $163^{\circ} \mathrm{C}$ is $4 \mathrm{~kW}$ (based on the difference in steady flow availability between the exhaust exit and environmental conditions.) The very low output rational efficiency (0.18) is typical of an SI engine and reflects the significant irreversibilities that are inherent in combustion and the rapid in-cylinder processes.

\subsection{Steady flow availability based on reversible heat transfer}

The exhaust gas from the engine is considered to be flowing through a heat exchange system in which heat transfer takes place through negligibly small temperature differences. Work production is done incrementally, where the high-temperature reservoir is at the temperature of heat transfer with a low-temperature reservoir temperature of $T_{0}$.

The work produced is then the change in steady flow availability between the heat exchange entry and exit conditions

$$
\begin{aligned}
\Delta b & =\left(h_{1}-h_{2}\right)-T_{0}\left(s_{1}-s_{2}\right) \\
& =c_{p}\left[\left(T_{1}-T_{2}\right)-T_{0} \ln \left(\frac{T_{1}}{T_{2}}\right)\right] \\
& =0.98\left[348-373 \ln \left(\frac{784}{436}\right)\right]=127 \mathrm{~kW} / \mathrm{kg}
\end{aligned}
$$

For an exhaust flow of $0.1 \mathrm{~kg} / \mathrm{s}$, this value of available energy corresponds to a work output of $12.7 \mathrm{~kW}$.

Because the analysis is based on a fluid power cycle, heat transfer is considered from the hot exhaust gases to a working fluid. There is a significant loss of available energy in the boiler where heat is transferred over large temperature differences. This loss of available energy that results from such a finite heat transfer is considered in the next section.

\subsection{Effects of realistic heat transfer}

In the present example, the temperature of water is increased from the feed temperature of $60{ }^{\circ} \mathrm{C}$ to the saturation conditions at $100 \mathrm{bar}$, that is, $311^{\circ} \mathrm{C}$ (or $584 \mathrm{~K}$ ). Over a conceptual length $L$, allowing for the relative heat transfer needed for heating to the saturation conditions, and then the subsequent evaporation, the 'pinch point' occurs at 0.42 of the total heat transfer length (on the assumption that the rate of cooling of gas with the length of the heat transfer is uniform). The temperature distribution is illustrated in Fig. 3.

The heating process takes place in two stages that could in turn be associated with (a) the engine cooling jacket and the lower-temperature section of

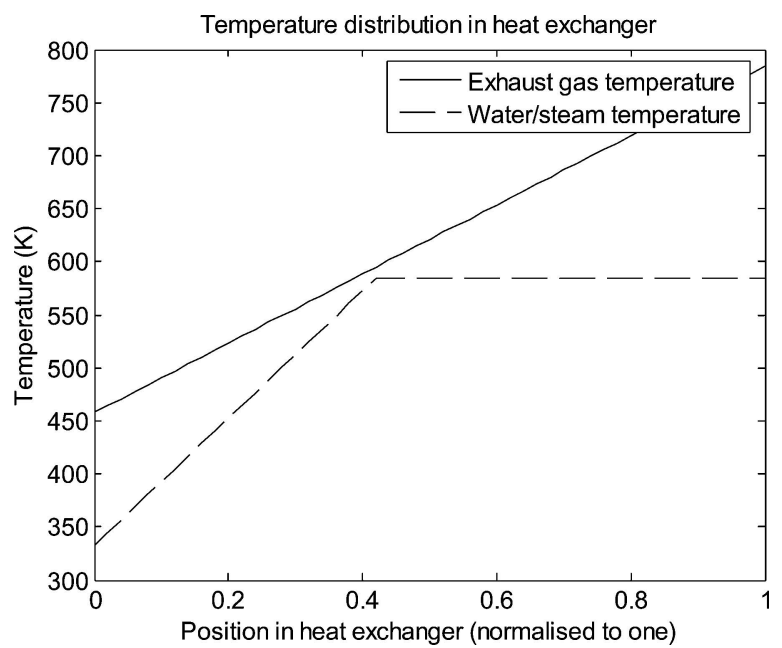

Fig. 3 Heat exchange temperature distributions (heat exchange dimension normalized to unity) 
the exhaust and (b) the high-temperature section of the exhaust. For the purposes of this analysis it is assumed that the initial heating ('economizer') brings the water close to saturation conditions, while the later stage of heating ('boiler') completes that process and causes the evaporation of steam that maintains a constant quality (say 0.1 ) in an accumulator. Because of the need to manage heat transfer over a large temperature difference, there is a lost opportunity for work that can be found by integrating the work that could be done if the heat transfer took place in a fully reversible way.

At each point along the heat exchanger, considering a short length, $\delta x$, the work that could be produced is

$$
\begin{aligned}
\delta W & =\dot{m} \eta_{\max } \delta Q=\dot{m}\left[1-\left(\frac{T_{\mathrm{L}}}{T_{\mathrm{H}}}\right)\right] c_{p} \delta T \\
& =\dot{m}\left[1-\left(\frac{T_{\mathrm{L}}}{T_{\mathrm{H}}}\right)\right] c_{p} \frac{\delta T}{\delta x} \delta x
\end{aligned}
$$

Integrating over the length of the heat exchanger, the shaft work that could be produced by a heat engine working reversibly is

$$
\begin{aligned}
W & =\dot{m} c_{p} \int_{0}^{L} \frac{\mathrm{d} T}{\mathrm{~d} x}\left[1-\left(\frac{T_{\mathrm{L}}}{T_{\mathrm{H}}}\right)\right] \mathrm{d} x \\
& =\dot{m} c_{p} k_{T} \int_{0}^{L}\left[1-\left(\frac{T_{\mathrm{L}}}{T_{\mathrm{H}}}\right)\right] \mathrm{d} x
\end{aligned}
$$

where $k_{T}$ is the constant temperature gradient on the high-temperature side of the heat exchanger, and $\dot{m} c_{p} k_{T}$ is the heat transfer per unit length of the heat exchanger which will be denoted below by $k_{q}$.

For the particular heat transfer case presented in this paper, $T_{\mathrm{L}}$ and $T_{\mathrm{H}}$ have the following values

$$
T_{\mathrm{H}}=458+\frac{326}{L} x
$$

and

$$
\begin{aligned}
& T_{\mathrm{L}}=333+\frac{598}{L} x, \quad 0 \leqslant x \leqslant 0.42 L \\
& T_{\mathrm{L}}=584, \quad 0.42 L<x \leqslant L
\end{aligned}
$$

The case where $T$ is an affine function of $x$, and the heat transfer per unit length is uniform along the length of the heat exchanger, gives the general solution to the lost work output as

$$
\begin{aligned}
& W_{\text {lost, economizer }} \\
& =k_{q}\left[\frac{m_{\mathrm{h}}-m_{1}}{m_{\mathrm{h}}}\left(x+\frac{c_{\mathrm{h}}}{m_{\mathrm{h}}}\right)\right. \\
& \left.\quad+\left(\frac{c_{\mathrm{h}} m_{1}-c_{1} m_{\mathrm{h}}}{m_{\mathrm{h}}^{2}}\right) \ln \left(x+\frac{c_{\mathrm{h}}}{m_{\mathrm{h}}}\right)\right]
\end{aligned}
$$

for the economizer section of the heat transfer process, and as

$$
W_{\text {lost, boiler }}=k_{q}\left[x-\left(\frac{c_{1}}{m_{\mathrm{h}}}\right) \ln \left(x+\frac{c_{\mathrm{h}}}{m_{\mathrm{h}}}\right)\right]
$$

for the boiler section.

Gradient and intercept values are shown in Table 1. Intercept $c_{1}$ is identical to $T_{\text {sat }}$, the operating temperature of the system. Substituting these values gives

$$
\begin{aligned}
& W_{\text {loss,economizer }} \\
& \quad=\left[\frac{-28.36}{L}(x+1.405 L)+53.04 \ln (x+1.405 L)\right]
\end{aligned}
$$

and

$$
W_{\text {lost, boiler }}=\left[\frac{34}{L} x-16.80 \ln (x+1.405 L)\right]
$$

yielding the numerical results $W_{\text {loss,economizer }}=1.96 \mathrm{~kW}$ and $W_{\text {loss,boiler }}=2.92 \mathrm{~kW}$.

Substituting $T$ for $c_{1}$ in the expression for lost work in the boiler gives the power loss (in $\mathrm{kW}$ ) as a function of $T$

$$
W_{\text {loss,boiler }}=19.72-0.029 T
$$

Locally, at the design conditions of the heat exchanger, the loss of available energy diminishes at a constant rate with temperature, so that a $10 \mathrm{~K}$ temperature increase in the boiler operating temperature would result in approximately $0.3 \mathrm{~kW}$ loss of useful work output. Diminishing the temperature difference would improve the overall efficiency but would change the

Table 1 Parameters of the temperature distribution (L, total length of the heat exchanger)

\begin{tabular}{lll}
\hline & \multicolumn{2}{c}{ Range of linear dimension, $x$} \\
\cline { 2 - 3 } & $0.42 \mathrm{~L}-\mathrm{L}$ & $0-0.42 \mathrm{~L}$ \\
\hline$m_{\mathrm{h}}$ & $326 / \mathrm{L}$ & $326 / \mathrm{L}$ \\
$c_{\mathrm{h}}$ & 458 & 458 \\
$m_{1}$ & 0 & $598 / \mathrm{L}$ \\
$c_{1}$ & 584 & 333 \\
\hline
\end{tabular}


dynamics of the system by diminishing the rate of heat transfer from the exhaust gas flow. The analysis leads to the conclusion that the heat exchange conditions will need to be dynamic and selected using optimization methods according to exhaust temperature.

It should be noted that this is a static analysis of steady flows in the boiler. The extension of the analysis to dynamic conditions is of great importance and will be the subject of a later paper.

\subsection{Steady flow availability based on heat transfer to a vapour power cycle}

Given that there must be heat transfer to a working fluid that must be evaporated, one way to evaluate the available work is to calculate the work output of an ideal vapour plant. Referring to Fig. 3, consider two work-producing devices, one exchanging heat at the saturation temperature corresponding to the operating pressure of the system, and the other a cluster of smaller devices that exchange heat at the exhaust temperature where its value is below the saturation temperature.

For the first device the maximum work output is given by the Carnot efficiency using the heat transfer made in the constant-temperature phase of the heating process

$$
\begin{aligned}
W_{\max } & =0.58 \times 34 \times\left(1-\frac{373}{584}\right) \\
& =0.58 \times 34 \times 0.361=7.12 \mathrm{~kW}
\end{aligned}
$$

For the second set of devices, each operates on an incremental length $\delta x$ in the economizer section, where the maximum work output is

$$
\delta W=\delta Q\left[1-\left(\frac{T_{\mathrm{L}}}{T_{\mathrm{H}}}\right)\right]
$$

Given that $\delta Q=k_{q} \delta x$, assuming a linear distribution of heat transfer, the total work is given by

$$
\begin{aligned}
W_{\max , 2} & =k_{q} \int_{0}^{0.42 L}\left[1-\left(\frac{T_{\mathrm{L}}}{T_{\mathrm{H}}}\right)\right] \mathrm{d} x \\
& =k_{q}\left[x-\frac{373 L}{326} \ln \left(x+\frac{458 L}{326}\right)\right]_{0}^{0.42 L} \\
& =4.08 \mathrm{~kW}
\end{aligned}
$$

The total is less than the available energy that was previously calculated owing to heat transfer over the finite temperature difference. The total is $11.2 \mathrm{~kW}$ as opposed to the available energy of $12.7 \mathrm{~kW}$. The difference of $1.5 \mathrm{~kW}$ is the loss due to the heat exchange over the finite temperature difference. Note that the work totals are not additive. If a workproducing device could be used between the exhaust and the vapour system, then the heat exchanged with the main work-producing devices would be diminished.

\subsection{Unsteady flow availability based on stored energy}

Consider first a reversible expansion from saturated steam at the working pressure to saturated water at condenser conditions ( $1 \mathrm{~atm}$ and $373 \mathrm{~K}$ ), state change 4 to 5 in Fig. 4 . The ideal work per unit mass of working fluid at the system working pressure is given by

$$
a_{4}-a_{0}
$$

There is still residual opportunity to do work using the water at condenser conditions

$$
a_{5}-a_{0}
$$

The ideal shaft work is simply the difference in the non-flow exergy, $a_{4}-a_{5}$. The base condition (state 5) is water at condenser conditions: $373 \mathrm{~K}$ and $1 \mathrm{~atm}$.

Consider now a heat transfer process to the water during which the water is evaporated and the resulting steam is pressurized to working pressure. This process requires mechanical work, as well as heat transfer. Once the accumulator is fully charged, the steam is expanded reversibly and shaft work is produced.

In Fig. 4, the changes in state are as follows:

(a) 1 to 2 - isentropic compression from saturation conditions at condenser pressure to the working pressure;

(b) 2 to 3 - heating at constant pressure to fully saturated water;

(c) 3 to 4 - evaporation to saturated steam at the working pressure;

(d) 4 to 5 - fully reversible expansion;

(e) 5 to 1 - condensation at constant pressure.

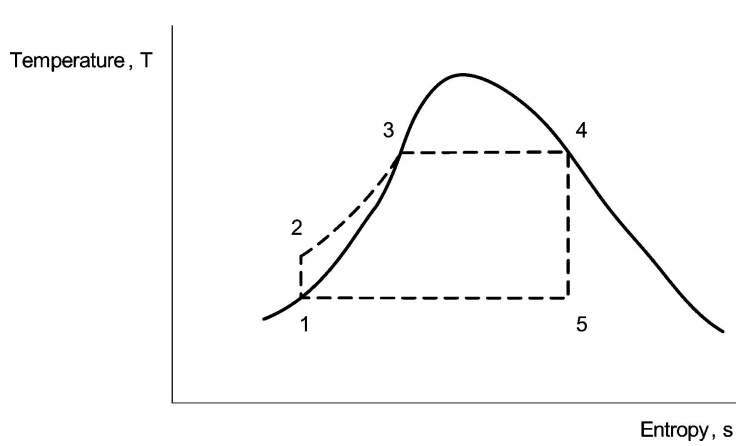

Fig. 4 Change in state during a compression - heating - expansion - condensation cycle 
The accumulated steam is expanded through a workproducing device. The resulting work output may be compared with the heat transfer from the exhaust system to give an effective efficiency

$$
\eta_{\text {total }}=\frac{W}{Q}
$$

The energy required to take a unit mass from the condenser state to the working state is

$$
u_{2}-u_{1}
$$

The change in internal energy is made up of two components, the work done to raise the pressure of the water and the heat transfer required fully to evaporate the water. Assuming an isentropic compression of the water

$$
T \mathrm{~d} s=\mathrm{d} u+p \mathrm{~d} v \Rightarrow \mathrm{d} u=-p \mathrm{~d} v=\mathrm{d} h-v \mathrm{~d} p
$$

The work contribution to the gain in internal energy is small (of the order of $1 \mathrm{~kJ} / \mathrm{kg}$ ) and can, for the purposes of this calculation, be neglected.

During the expansion process, the work that may be recovered is the change in non-flow exergy, given by

$$
a_{1}-a_{2}=\Delta u+p_{0} \Delta v-T_{0} \Delta s
$$

The numerical values and approximate efficiency are given in Table 2. Note that the work output would be reduced if a realistic expander efficiency were proposed.

Efficiency improves with increasing pressure. Greater work per unit mass of expanding steam is done as the pressure is increased, but at a cost of heat transfer needing to be done at the higher temperatures corresponding to the higher pressures.

Raising the pressure of the accumulator to a working pressure and then discharging it fully is an extreme case of usage and would suit the use of the system to provide a low power output over a long period. A better assessment of the potential of the unsteady mode of operation can be made by considering incremental heat transfer and subsequent development of shaft work. This is the subject of the next stage of analysis.

\subsection{Unsteady flow availability based on intermittent heat transfer}

In the more realistic process the system operates at a constant working pressure. Short periods of heat transfer result in a change in state of the fluid. An increment of work can now be extracted whose net result is to return the system to its original state. It will be assumed that the accumulator is at saturation conditions, and that, as heat is transferred, steam is expanded to produce work. With a heat transfer, $\delta q$, there is an increase in internal energy, $\delta u$. This gain results in a change in the mass fraction within the accumulator present as steam. A mass of steam, $\delta m$, is expanded reversibly, resulting in $\delta W$ of shaft work.

The heat transfer results in a change in the nonflow exergy which in turn is a measure of the work available. It is this increase, $\delta a$, that, when compared with the heat transfer, gives a measure of efficiency

$$
\eta_{\mathrm{th}}=\frac{\delta a}{\delta q}
$$

The value of $\delta a$ can be calculated from the change in state that follows the reversible heat transfer. At saturated conditions, the only change in state is the evaporation of a small quantity of liquid water to steam at saturation conditions.

Therefore, given that $a \equiv u+p_{0} V-T_{0} s$, the change in available energy

$$
\delta a=\delta u+p_{0} \delta V-T_{0} \delta s=\delta Q+p_{0} \delta V-T_{0} \delta s
$$

so that the highest achievable efficiency

$$
\eta_{\max }=\frac{\delta a}{\delta Q}=1-\left(\frac{T_{0} \delta s-p_{0} \delta V}{\delta Q}\right)=1-\frac{T_{0}}{T}+\frac{p_{0} \delta V}{\delta Q}
$$

The value of $\eta_{\max }$ is shown in Fig. 5 as a function of operating pressure. The value increases with increasing pressure as the effective heat exchange temperature for a conceptual power cycle increases. However, there is a counteracting effect that is evident in this application; that is, as the pressure increases, so does the operating temperature of the system, in

Table 2 Efficiency summary for accumulator operation

\begin{tabular}{llllll}
\hline Working pressure (bar) & $\Delta u(\mathrm{~kJ} / \mathrm{kg})$ & $\Delta v\left(\mathrm{~m}^{3} / \mathrm{kg}\right)$ & $\Delta s(\mathrm{~kJ} / \mathrm{kg} \mathrm{K})$ & $\Delta a(\mathrm{~kJ} / \mathrm{kg})$ & $\eta$ \\
\hline 10 & 2164 & 0.193 & 5.28 & 213.86 & 0.099 \\
20 & 2181 & 0.098 & 5.03 & 314.61 & 0.144 \\
30 & 2185 & 0.066 & 4.88 & 371.36 & 0.170 \\
40 & 2186 & 0.049 & 4.77 & 411.69 & 0.188 \\
50 & 2180 & 0.038 & 4.67 & 441.52 & 0.203 \\
60 & 2173 & 0.031 & 4.59 & 464.03 & 0.214 \\
\hline
\end{tabular}




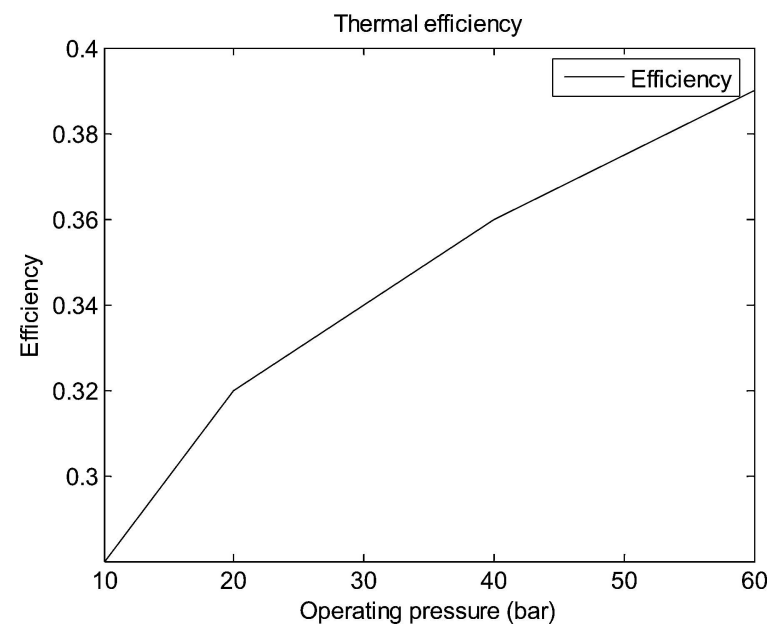

Fig. 5 Thermal efficiency as a function of operating pressure

turn reducing the heat transfer rate from the stream of engine exhaust gas.

Simply multiplying the maximum efficiency by the temperature difference produces a variable that is proportional to the maximum work output from the stream of exhaust gas. This is shown in Fig. 6, where a clear maximum value can be seen at about 20 bar. The pressure corresponding to the maximum value will increase as the average exhaust temperature increases.

\section{EXPANSION OF THE STEAM}

\subsection{Work production and losses}

Expansion of the steam takes place in one or more stages. One practical realization of an expander is in a compound form in which steam is expanded and flows to subsequent stages. In steam power systems of the past, up to four stages of expansion have been employed [see reference [9] for examples], although expanding fully to condenser pressure was seldom attempted and in later developments a turbine was used for the final stages of expansion. In a more recent project concerned with specifying expansion technology for a passenger car application [10], the designers opted for a single-expansion engine on the basis that the interstage throttling losses would be greater than any gain resulting from compounding.

The analysis presented here is intended to establish guidelines and for the most part (unless stated) considers reversible steps and perfect gas behaviour (though with a ratio of specific heats of 1.333 to reflect steam properties). The conclusions will be approximate but appropriate for the objective of establishing control guidelines for the system. The reciprocating expander is chosen for its analysis because it represents an accessible, low-cost, and relatively unexplored technology for small-scale expansion applications.

In a single-stage expansion, with a boiler pressure of $p_{1}$ and a condenser pressure of $p_{2}$ (see Fig. 7 for a representation of the pressure-volume diagram), state 1 is at top dead centre, state 2 is at inlet valve closure, and state 3 is at bottom dead centre. Exhaust valve closure is marginally before bottom dead centre. Just after exhaust valve opening, the pressure drops quickly to the exit pressure.

1. The work done on the piston while the inlet valve is open is due to boiler pressure acting on the piston.

2. Once the inlet valve is closed, the steam expands to the full travel of the piston.

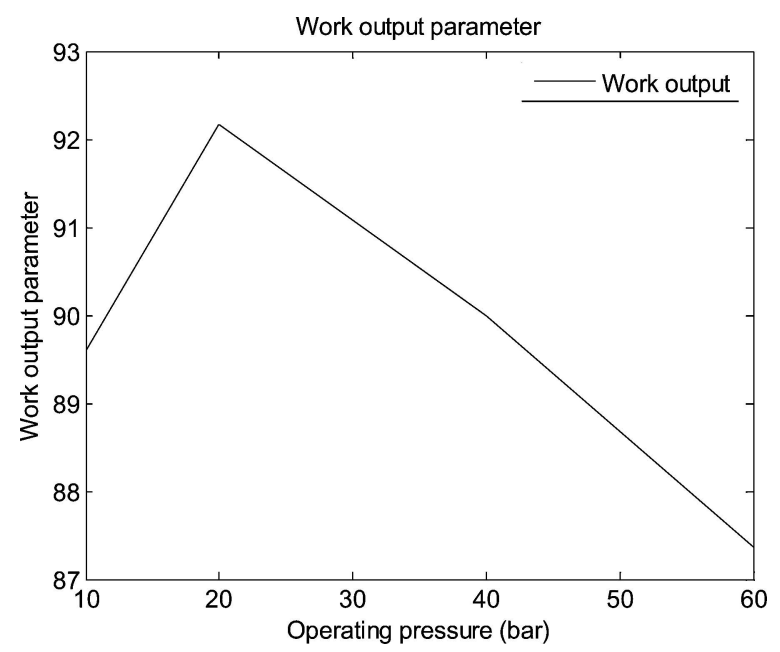

Fig. 6 Combined measure of efficiency and heat transfer rate

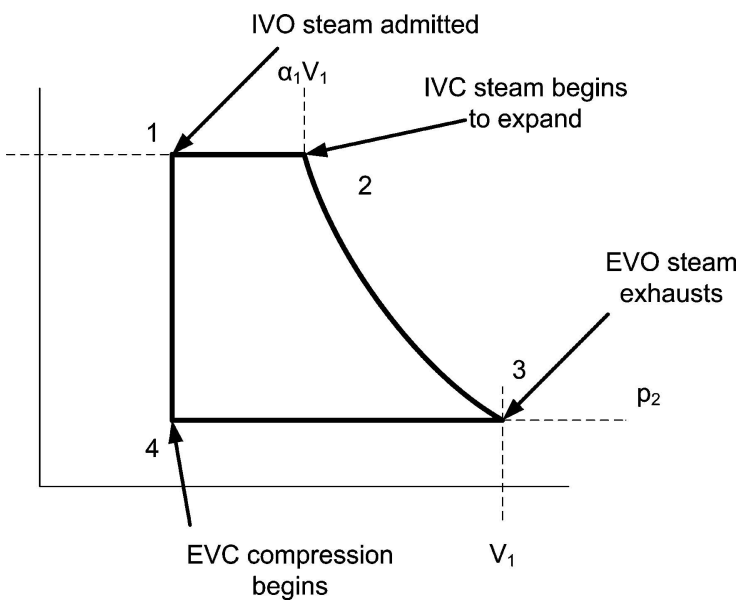

Fig. 7 Single-stage steam expansion process 
As the engine speed increases, the $p-V$ diagram becomes progressively more rounded, indicating a progressive reduction in the cycle work. The rounding is due to flow and heat transfer effects which are all indicative of irreversibilities.

The work output is controlled by varying the steam admitted into the high-pressure cylinder. The control variable is defined in terms of the proportion of the volume into which steam at boiler pressure is admitted and is termed the cut-off (or cut-off ratio) and denoted by $\alpha$.

Assuming polytropic expansion with index $n$, so that $p V^{n}=k=p_{1}(\alpha V)^{n}$, and with the valve cut-off set to $\alpha$, the work done up to exhaust valve opening is

$$
\begin{aligned}
W_{1}= & p_{1} \alpha V+\int_{\alpha V}^{V} p \mathrm{~d} v=p_{1} \alpha V \\
& +\frac{p_{1}(\alpha V)^{n}}{1-n}\left(V^{1-n}-\alpha^{1-n} V^{1-n}\right) \\
= & \left(\frac{1}{1-n}\right) p_{1} V\left(\alpha^{n}-n \alpha\right)
\end{aligned}
$$

Taking the simplifying step of a rapid rise in the cylinder pressure (see Fig. 7), the negative work done by the piston on the steam during the exhaust process is simply the product of exhaust pressure and the swept volume of the piston

$$
W_{2}=p_{2} V
$$

The total work per cycle is therefore

$$
W_{\text {total }}=W_{1}-W_{2}=\left(\frac{1}{n-1}\right) p_{1} V\left(n \alpha-\alpha^{n}\right)-p_{2} V
$$

Note that the expansion is from the boiler pressure $p_{1}$ to the exit pressure (and the entry pressure to subsequent expansion steps) $p_{2}$.

Since $p_{2} V^{n}=p_{1} \alpha^{n} V^{n}$, the expression can be simplified to

$$
\begin{aligned}
W_{\text {total }} & =\frac{p_{1} V}{1-n}\left[\alpha^{n}-n \alpha-(1-n) \alpha^{n}\right] \\
& =\left(\frac{n}{n-1}\right) p_{1} V\left(\alpha-\alpha^{n}\right)
\end{aligned}
$$

The value of $W_{\text {total }}$ as a function of the cut-off ratio $\alpha$ is shown in Fig. 8. Note that the compression of steam remaining in the cylinder is considered both brief and abrupt. The use of a very short compression leads to a small overestimate of the work done per cycle, but one that will not change the main conclusions. This assumption was common practice in steam engine design. See reference [9, pp. 128-140] for examples.

The maximum value of work, $W_{\max }$, corresponds to $\mathrm{d} W / \mathrm{d} \alpha_{1}=0$, or to $\alpha_{1}=\sqrt[n-1]{1 / n} \approx 0.42$ for steam.

The maximum value of the work output at a cutoff value of about 0.4 comes about because of two competing effects. As the cut-off value increases, more steam is let into the cylinder. After expansion, the return stroke of the piston is against the pressure at the end of the expansion. Consequently, as the cut-off lengthens (increasing the work), so the pressure at the end of expansion increases and the losses due to a return stroke increase. The two competing effects lead to the optimum value.

Note that the optimum cut-off ratio is only a function of fluid properties. The dependence on only the value of the index of expansion means that the optimum can be estimated differently depending on the state of the steam. At the optimum value of cut-off the expansion is both isentropic and matched to the cylinder volume. Away from the optimum, the expansion can still be isentropic but is not matched to the volume of the cylinders. By effectively reducing cylinder volume through the use of variable exhaust valve timing, the operation can be kept close to the optimum.

At the optimum cut-off, there are no further control degrees of freedom. Increasing cut-off will lead to uncontrolled expansion at the end of the expansion stroke. While work production will increase, the efficiency of steam usage will drop.

At lower loads and less than the optimum cut-off value, the exhaust valve can be opened at a pressure corresponding to condenser conditions, effectively reducing the cylinder volume and eliminating uncontrolled expansions between the cylinder, condenser, and boiler.

Adding cylinders to create successive expansions offers both thermodynamic and control advantages. Work can be dynamically allocated between cylinders, for example, by choice of valve timing events. In the next sections, an analysis of the relative significance of the expander variables will form the basis for an investigation of the controllability of a compound expansion system.

The mode of operation of the expander determines the effectiveness of steam usage. As an example, consider a system working at 30 bar. For the highest torque output the cut-off is increased to unity, and the piston of the high-pressure cylinder is exposed to boiler pressure for its full stroke. As the torque requirement is reduced, the cut-off ratio will be reduced. At unity cut-off, the specific work output is $200 \mathrm{~kJ} / \mathrm{kg}$. At $\alpha=0.25$, the specific work output has 
increased to $292 \mathrm{~kJ} / \mathrm{kg}$. The torque, however, has fallen to 40 per cent of the value at unity cut-off. A short-term torque requirement can be met, but with a loss of available energy.

\subsection{Compound expansion}

\subsubsection{Why compound operation?}

The optimum form of expansion would be in a single step from the inlet conditions to the condenser inlet pressure in which the expansion takes place very slowly. In practice, and working at realistic speeds, each expansion step has inherent irreversibilities. Given that, in this application, the steam is starting in a saturated state and becoming progressively wetter, the larger the expansion step, the greater is the possibility of inhomogeneous conditions, and consequently of irreversible heat transfer, and mass transfer by virtue of changes in density.

A series of expansion steps would reduce the degree of loss by reducing the dynamic effects that lead to irreversibilities. In all practical systems there will be small irreversibilities associated with finite temperature differences, with pressure losses through throttling, and with pressure differences introduced during valve opening events.

Referring again to Fig. 7, consider an expansion from boiler pressure to exit pressure $p_{2}$. The expansion stops as the exhaust valve opens and the piston reverses direction at the fullest extent of its stroke. The lost work in this expansion is represented by the expansion that would continue if the piston could move until the cylinder pressure precisely matched the downstream pressure. Assuming perfect gas behaviour with a polytropic index of $n$, the lost work is

$$
\begin{aligned}
W_{\text {loss }} & =\int_{V}^{V_{\mathrm{f}}} p \mathrm{~d} V \\
& =\frac{1}{n-1} \alpha^{n-1} V^{n-1}\left[\left(\frac{p_{1}}{p_{2}}\right)^{(n-1) / n}-\alpha^{1-n}\right]
\end{aligned}
$$

where $V_{\mathrm{f}}$ is the volume of the cylinder where the pressure of the steam has fallen to exit pressure.

The lost work $W_{\text {loss }}=0$ when either $\alpha=0$ (no steam enters the cylinder) or $p_{2}=\alpha^{n} p_{1}$. This second condition is where the expansion in the cylinder is such that the pressure of the gases at the end of the (isentropic) expansion stroke is equal to the exit pressure $p_{2}$.

The case of a two-stage expansion illustrates the issues in balancing the work output of the cylinders while minimizing irreversibilities. In the ideal, reversible case the following conditions prevail.
1. The steam in each cylinder is fully expanded to the exit pressure.

2. The passage of steam between stages is without loss due to throttling or friction and mixing losses in connecting pipework.

Each stage has independent cut-off ratios that are selected to balance the work output and the exit pressure from the first stage.

In practice the operation of the expander needs to be more flexible than the requirements for reversible operation would permit. The steam coming from the accumulator may be throttled to ensure that it is subsequently fully expanded. Throttling may drop the pressure but, starting from saturated conditions, results in dry steam with a moderate degree of superheat. Superheat contributes to higher efficiency in operation as condensation to wet steam results in a higher dryness fraction at the condenser temperature and consequently fewer losses during expansion.

Figure 9 shows two successive expansion cycles with initial pressure $p_{1}$ and final pressure $p_{3}$. The intermediate pressure $p_{2}$ is set by $\alpha_{1}$ as $p_{2}$ is the pressure reached through an isentropic expansion from the supply pressure $p_{1}$ after the inlet valve closes.

\subsubsection{Degrees of freedom in a compound arrangement}

The purpose of the analysis presented here is to understand the degrees of freedom that a multicylinder arrangement offers and their implications for design and for the operation of the system. The degrees of freedom will be expressed in different ways depending on the design objectives. Table 3 shows the variables, their significance, and interrelationship.

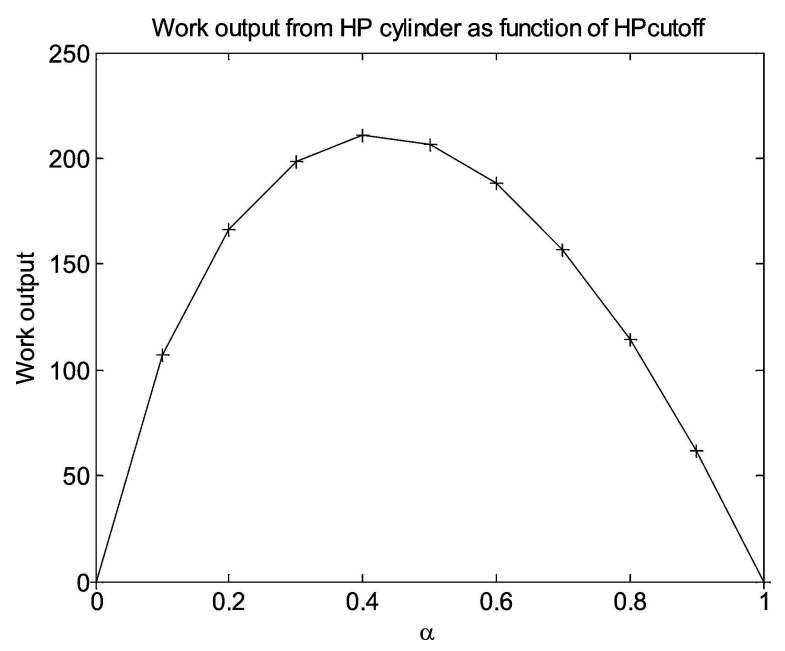

Fig. 8 Specific work $(J / \mathrm{kg})$ output as a function of the high-pressure cut-off ratio 


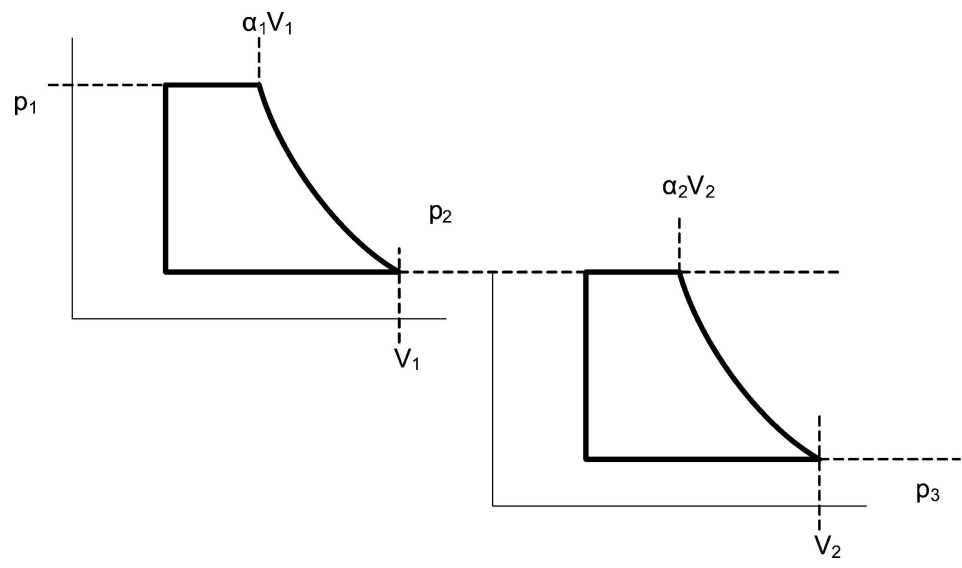

Fig. 9 Two-stage expansion represented by $p-V$ diagrams

Table 3 Control and design variables in a compound expansion system

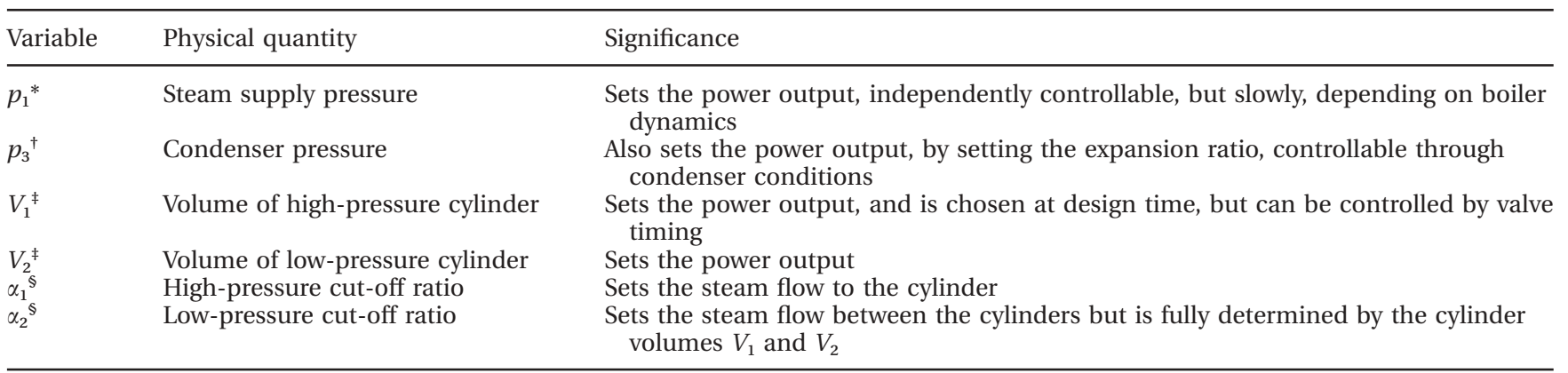

$* p_{1}$ is an independent variable and will be decided upon at design time; however, it is possible to vary $p_{1}$ in order to change the work output; $p_{1}$ appears as a multiplier in the work output of the system.

${ }^{\dagger} p_{3}$ is also fixed by design but can be varied by, for example, the degree of cooling applied to a condenser.

${ }^{\ddagger}$ Both $V_{1}$ and $V_{2}$ are fixed by design in the sense of their maximum capacity; however, by use of variable exhaust valve timing, the volumes can be effectively decreased.

${ }^{\S}$ Both $\alpha_{1}$ and $\alpha_{2}$ are controllable during operation of the engine; $\alpha_{1}$ is the primary variable as, through choice of its value, the amount of steam admitted to the system is controlled; $\alpha_{2}$ is much more heavily constrained and, to minimize losses, will be identical to the cyclinder volume ratio.

In the analysis that follows, the constraints that apply to isentropic operation are first identified. Then the use of the independent variables is considered in relation to a number of operating goals.

For the high-pressure cylinder (cylinder 1)

$$
p_{1}\left(\alpha_{1} V\right)^{n}=p_{2} V_{1}^{n} \Rightarrow p_{2}=\alpha_{1}^{n} p_{1}
$$

while for the low-pressure cylinder (cylinder 2)

$$
p_{2}\left(\alpha_{2} V_{2}\right)^{n}=p_{3} V_{2}^{n} \Rightarrow p_{3}=\alpha_{2}^{n} p_{2}
$$

For volume flow continuity between cylinders

$$
\alpha_{2} V_{2}=V_{1}
$$

and from the pressure relationships

$$
p_{3}=\alpha_{1}^{n} \alpha_{2}^{n} p_{1}
$$

These equations form the essential constraints for the subsequent analysis. The following sections consider the way in which the constraints can be phrased to achieve certain performance objectives. These are as follows:

(a) work balance - dividing the overall work output between the cylinders;

(b) operation at optimal conditions;

(c) achieving a specified load by choice of cut-off ratio.

Each will be considered in turn.

\subsubsection{Achieving performance requirements}

Work balance. In practice it is desirable to balance the torque contribution from each cylinder of an engine. If, however, this results in a either a volume discrepancy between the two cylinders or poor thermodynamic conditions in the low-pressure cylinder, that equality may have to be compromised. 
Considering first the case of equal load distribution, balancing the power output equally between the two cylinders gives equation (33) with the polytropic coefficient assumed to be the same for both expansions

$$
W_{1}=W_{2} \Rightarrow p_{1} V_{1}\left[\alpha_{1}-\alpha_{1}^{n}\right]=p_{2} V_{2}\left[\alpha_{2}-\alpha_{2}^{n}\right]
$$

Substituting the pressure and volume relationships

$$
\frac{1}{\alpha_{1}^{n}}\left[\alpha_{1}-\alpha_{1}^{n}\right]=\frac{1}{\alpha_{2}}\left[\alpha_{2}-\alpha_{2}^{n}\right]
$$

Simplifying and rearranging yields

$$
\alpha_{1}^{1-n}-1=1-\alpha_{2}^{n-1}
$$

Substituting from equation (32) $p_{3} / p_{1}=\alpha_{1}^{n} \alpha_{2}^{n}$

$$
\alpha_{1}^{n-1}=\frac{1+\left(p_{3} / p_{1}\right)^{1-1 / n}}{2}
$$

Where it is desirable to change the balance of the work between the cylinders, it is possible to introduce a constant, $k \leqslant 1$, so that $W_{2}=k W_{1}$.

Following the same procedure gives the expression

$$
\alpha_{1}^{n-1}=\frac{k+\left(p_{3} / p_{1}\right)^{1-1 / n}}{k+1}
$$

Note that $\alpha_{1}$ is fully determined once the pressure ratio is decided. The cut-off ratio of the second cylinder, $\alpha_{2}$, is determined by the mass flow of the two cylinder volumes. Figure 10 shows the cut-off value as a function of the overall pressure ratio and is plotted for both equal work distribution and then with the low-pressure work reduced to half the high-pressure work.

As expected, the cut-off value is reduced to 0.75 of the starting value. The implication is that the

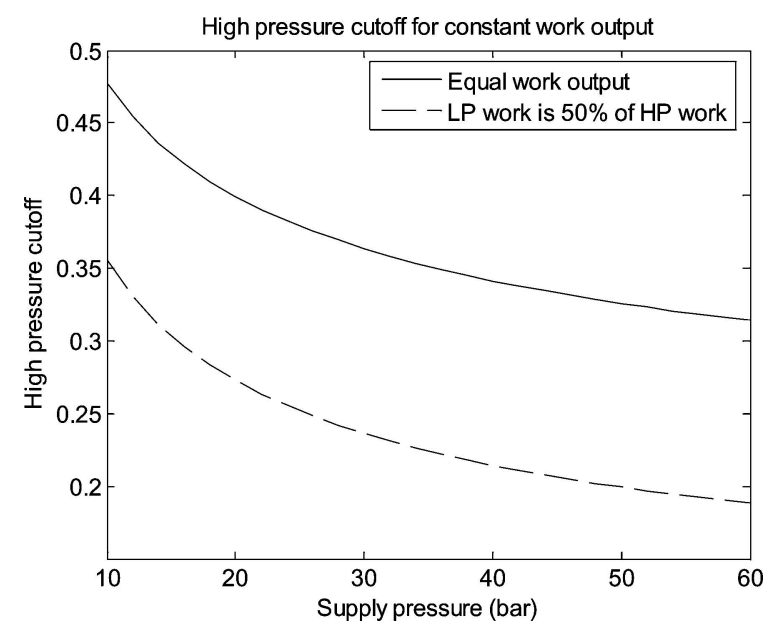

Fig. 10 High-pressure cut-off value as a function of system operating pressure low-pressure cylinder is reduced to half its volume. This same effect can be achieved by simply opening the exhaust valve early.

Consider the case where the total work is $W$ and the condenser pressure is $p_{3}$ and is fixed. (In practice, by actively varying the cooling rate of the condenser, the value of $p_{3}$ can be controlled.) The cylinder volumes are also fixed with $V_{2}=k V_{1}$.

The resulting governing equation is

$$
W=\left(\frac{n}{n-1}\right) V_{1}\left(p_{1} \alpha_{1}\right)-k p_{3} V_{1}
$$

The boiler pressure and cut-off ratio act in inverse proportion. As expected, the work is proportional to the volume of the high-pressure cylinder, $V_{1}$, and the absolute work done is controllable through the cut-off value, $\alpha_{1}$, or boiler pressure or both. As the torque demand on the expander increases, it can be met by an increase in boiler pressure or cut-off ratio. Cut-off is much faster as a control variable and points to a control architecture in which the error can be corrected in the short term by cut-off and in the longer term by pressure management.

Working at optimal conditions. In section 5.1 it was shown that there was an optimal cut-off ratio for the high-pressure cylinder. Implicitly that choice of cut-off ratio changed the intermediate pressure $p_{2}$. There is no corresponding optimal operating point for the system as a whole, and, by inspection of the equation for work output for the entire system, work output continues to increase with $\alpha_{1}$ or with $p_{1}$.

Taking a wider perspective of finding an optimal design for the expander system, there are other avenues to be explored, including the selection of both $p_{3}$ and $V_{2}$. The design load of the system is considered to be that where, at the nominal operating pressure $p_{1}$, the expander could be operated reversibly. At higher loads the exhaust valve timing could not be further retarded and would result in uncontrolled expansion of steam into the exhaust system and thence the condenser.

In order to illustrate the possibilities offered by both design and operating degrees of freedom in operating the expander in a flexible way, consider the following scenarios.

1. $p_{1}, V_{1}, V_{2}$ fixed. The operating pressure and geometry are selected; $p_{3}$ must be selected and controlled in order to control the work split between the cylinders.

2. $p_{1}, V_{1}$ fixed; $V_{2}$ variable through choice of exhaust timing. The variable low-pressure volume allows 
the work split to be controlled; $p_{3}$ may be fixed (through the design and operation of the condenser).

3. $V_{1}$ fixed, $\alpha_{1}$ fixed at the optimal value for the highpressure cylinder. For each $p_{1}$ there is a $p_{2}$ value dictated by $\alpha_{1}$. So long as $V_{2}$ is sufficiently large, the exhaust timing of the low-pressure cylinder can be selected to match the $p_{3}$ value.

The scope for selecting control settings up to design load allows flexibility for work allocation between the cylinder or maximizing the work output of the high-pressure cylinder in particular. In practice, the ability to vary $p_{1}$ and $p_{3}$ may be limited. However, both pressures have the potential to offer flexibility in the control policy.

Working at higher than design loads. At loads less than the design load, the cut-off ratio for the highpressure cylinder is reduced, limiting the mass of steam that flows into the cylinder. The cut-off ratio for the second cylinder is also reduced. The exhaust valve timing for the high-pressure cylinder is advanced so that the steam is exhausted at the correct intermediate pressure and the condenser pressure. In other words, the cylinders are simply reduced in their effective swept volume.

At higher than design loads, the volume of steam must be increased, and this is achieved by increasing the cut-off ratio of the high-pressure cylinder. Using availability as the basis, the decision must be made between:

(a) raising the intermediate pressure, $p_{2}$, and exhausting steam at higher than condenser pressure;

(b) enhancing the system pressure, $p_{1}$, and maintaining the cut-off ratios.

The second option can be conducted in a reversible manner, but in practice would be slow. The first option will allow a short-term adjustment to the work output to meet a temporary additional demand or to reduce the steam volume in anticipation of a sustained period of operation at high load. An important question concerns whether the work gain from increasing the cut-off ratio is greater than the work loss from the unconstrained expansion of the steam exhausted from the low-pressure cylinder.

The total work output from both cylinders is

$$
W_{\mathrm{tot}}=\left(\frac{n}{n-1}\right)\left(p_{1} V_{1}\left[\alpha_{1}-\alpha_{1}^{n}\right]+p_{2} V_{2}\left[\alpha_{2}-\alpha_{2}^{n}\right]\right)
$$

Using equation (32) and substituting for $p_{2}$ and $\alpha_{2}$, gives

$$
W_{\mathrm{tot}}=\left(\frac{n}{n-1}\right)\left[p_{1} V_{1} \alpha_{1}-p_{3} V_{2}\right]
$$

The two terms in the square brackets reflect the initial work done on the piston by the incoming steam, that is, at boiler pressure for the duration of the inlet valve opening, and the work done by the piston on the exhaust steam during the exhaust stroke. Parameters $p_{3}$ and $V_{2}$ are linked in the sense that, by deciding $p_{3}$ through the choice of the condenser conditions, $V_{2}$ is determined through the need to expand in the low-pressure cylinder to just that pressure. For given high-pressure conditions (pressure, volume, and cut-off ratio), $p_{3}$ and $V_{2}$ vary in inverse proportion.

The rate of change in work with respect to the control variable (given $p_{3}$ and $V_{2}$ as fixed)

$$
\frac{\mathrm{d} W_{\text {tot }}}{\mathrm{d} \alpha_{1}}=\left(\frac{n}{n-1}\right) p_{1} V_{1}
$$

As operation moves away from the optimal conditions, that is, the expansion in the high-pressure cylinder finishes close to the manifold pressure, it is essential that the work output gain through use of more steam (with a high cut-off value) is greater than the energy loss caused by an uncontrolled expansion of steam into the condenser.

Using the relationship $T_{3} / T_{1}=\left(p_{3} / p_{1}\right)^{(n-1) / n}$ gives

$$
\frac{T_{3}}{T_{1}}=\left(\alpha_{1} \alpha_{2}\right)^{n-1}
$$

As the expansion is isentropic, the loss of available work is simply the enthalpy difference between conditions at state 3 , the end of expansion and the condenser inlet. The enthalpy difference is $\Delta h=$ $c_{p}\left(T_{3}-T_{\text {cond }}\right)$, so that

$$
\frac{\partial W_{\text {loss }}}{\partial \alpha_{1}}=c_{p} \frac{\mathrm{d} T_{3}}{\mathrm{~d} \alpha_{1}}=c_{p} T_{1}(n-1) \alpha_{1}^{n-2} \alpha_{2}^{n-1}
$$

To evaluate the relative size of the work gain and the loss of available energy, the ratio

$$
\begin{aligned}
\frac{\mathrm{d} W_{\text {tot }}}{\mathrm{d} W_{\text {loss }}} & =\frac{\mathrm{d} W_{\text {tot }} / \mathrm{d} \alpha_{1}}{\mathrm{~d} W_{\text {loss }} / \mathrm{d} \alpha_{1}}=\frac{[n /(n-1)] p_{1} V}{c_{p}\left(\mathrm{~d} T_{3} / \mathrm{d} \alpha_{1}\right)} \\
& =\frac{R}{c_{p}} \frac{n}{(n-1)^{2}} \frac{\alpha_{1}^{2-n}}{\alpha_{2}^{n-1}}
\end{aligned}
$$

is formed. Note how the ratio is independent of pressure and cylinder volume and depends only on the gas properties through the value of $n$, the ratio of the cylinder volumes, $\alpha_{2}$, and the high-pressure cut-off ratio, $\alpha_{1}$. 
For steam $R=0.462 \mathrm{~kJ} / \mathrm{kg} \mathrm{K}, c_{p}=1.92 \mathrm{~kJ} / \mathrm{kg} \mathrm{K}$, and $n=4 / 3$, so that $\mathrm{d} W_{\text {tot }} / \mathrm{d} W_{\text {loss }}=3.63 \alpha_{1}^{2-n}$, which has a value greater than unity for $\alpha_{1}>0.15$. That is, for most of the range of $\alpha_{1}$, the gain in work output exceeds the losses.

As the system exceeds its design load, the use of high-pressure cut-off to meet the load requirement is an effective strategy. Sustained periods of high load would, however, be better met by an increase in the supply pressure $p_{1}$ or a reduction in $p_{3}$. This strategy would recover the thermal efficiency and allow the cut-off ratio to be kept close to an optimum value.

\section{AVAILABILITY IN THE INTEGRATED SYSTEM}

In the integrated system there are several variables that have a significant effect on the overall performance of the system. These variables include:

(a) exhaust gas temperature and flowrate (see section 6.1);

(b) operating pressure (see section 6.2);

(c) steam dryness fraction (see section 6.3).

\subsection{Exhaust gas temperature and flowrate}

The engine exhaust temperature will vary principally according to the engine load. The corresponding available energy is a strong function of exhaust temperature. The engine therefore has a significant control over the energy made available for recovery. Previous analysis has shown that access to this energy is limited by the nature of the recovery system and by practical factors such as heating and cooling of the heat transfer devices.

In the design of a thermal recovery system, the values of exhaust temperature will play a significant role and indicate the importance of balancing work output from the engine (through, for example, delayed exhaust valve opening) and the work potential from higher exhaust temperatures. A detailed evaluation of this process lies beyond the scope of this paper. However, the importance of a system-wide view of energy recovery is reinforced. Figure 11 shows how the availability is practically linear in the temperature range of interest, allowing a ready evaluation of the energy available according to engine load regimes.

\subsection{Operating pressure}

Changing the operating pressure of the system has both a transient effect and an effect in the steady state. The transient effect is due to either evaporation or condensation that takes place after the pressure

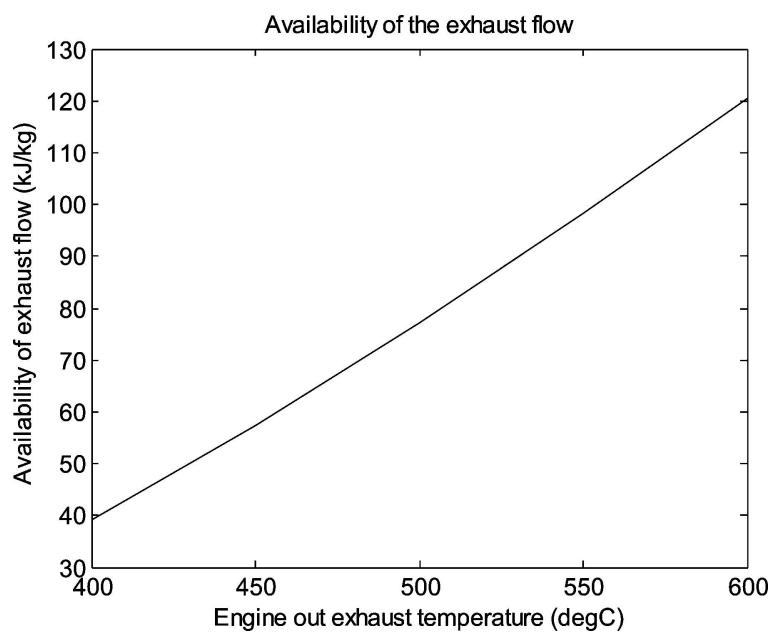

Fig. 11 Exhaust flow availability as a function of temperature

change. A pressure increase will lead to condensation corresponding to an adiabatic compression of the entire system. Likewise, a pressure decrease will lead to evaporation and an increase in the volume of steam available. Both require heat transfer so that the effects are not instantaneous and are governed by the heat capacity and heat transfer capability of the system. A practical implementation will be heavily insulated, so that, for the purposes of the analysis presented in this paper, heat transfer will be considered as taking place only within the economizer and boiler.

In the steady state, pressure relates directly to availability. The steam-water mixture maintained at a higher pressure will have a higher availability per unit mass and therefore be a more effective energy store. The energy is more accessible for a given expander size. As the pressure is reduced, so the heat transfer rate from the exhaust flow will increase as the water temperature falls. However, too high a temperature difference has two disadvantages: the large finite temperature difference represents a significant irreversibility, and the boiler can enter a vigorous boiling regime, with a consequent loss of effective heat transfer surface.

Consider a 501 capacity system operating at 20 bar with 50 per cent steam and water by mass. The total mass of water and steam, $m$, is about $1 \mathrm{~kg}$. An isentropic compression to 21 bar is governed by

$$
T \mathrm{~d} s=\mathrm{d} u+p \mathrm{~d} v
$$

but as $\mathrm{d} s=0$

$$
\mathrm{d} W=p \mathrm{~d} v=\mathrm{d} u
$$


Data are as follows:

\begin{tabular}{llll}
$\begin{array}{l}\text { Pressure } \\
\text { (bar) }\end{array}$ & $\begin{array}{l}\text { Temperature } \\
\left({ }^{\circ} \mathrm{C} / \mathrm{K}\right)\end{array}$ & $\begin{array}{l}\text { Dryness } \\
\text { fraction }\end{array}$ & $\begin{array}{l}u \\
(\mathrm{~kJ} / \mathrm{kg})\end{array}$ \\
\hline 20 & $212.4 / 485.4$ & 0.5 & 1752.2 \\
21 & $214.9 / 487.9$ & 0.499 & 1756.0
\end{tabular}

The rate of work input to the change in pressure

$$
\frac{\partial p}{\partial W}=\frac{1}{m} \frac{\partial p}{\partial u} \approx \frac{1}{3.8}=0.26 \mathrm{bar} / \mathrm{kJ}
$$

However, as the pressure increases (and also therefore the temperature), so the available energy from the exhaust stream increases

If the exhaust energy flow is $34 \mathrm{~kW}$, the rate of work output at 20 bar is at the maximum possible

$$
34 \eta=34\left(1-\frac{298}{485.4}\right)=13.13 \mathrm{~kW}
$$

At 21 bar, and assuming the same exhaust energy flow, the maximum possible work output is

$$
34 \eta=34\left(1-\frac{298}{487.9}\right)=13.23 \mathrm{~kW}
$$

At this power output, and assuming that steam is being expanded from the working pressure to 1 bar, at an isentropic efficiency of 0.85 , the mass flow of water at steady state will satisfy

$$
\dot{m}\left(h_{4}-h_{5}\right)=P
$$

where $h_{5}$ corresponds to the actual exit condition of the expander, where an isentropic expansion would be completed at state $5 \mathrm{~s}$ in Fig. 12.

At $20 \mathrm{bar}$, the isentropic work out is $506 \mathrm{~kJ} / \mathrm{kg}$ and the corresponding actual work is $430 \mathrm{~kJ} / \mathrm{kg}$. The mass flow of water is $13.13 / 430=30 \mathrm{~g} / \mathrm{s}$. The corresponding

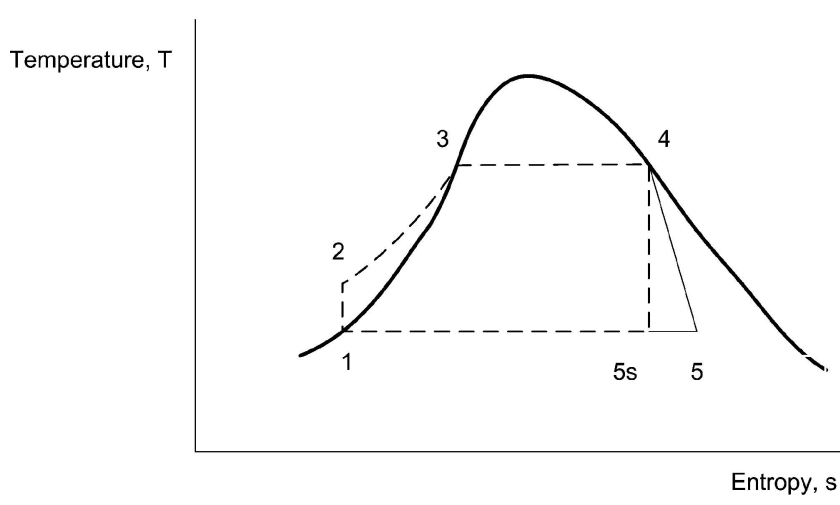

Fig. 12 Temperature entropy diagram of the working cycle, showing both an isentropic and a realistic expansion pump work is then

$$
P_{\text {pump }}=\frac{\dot{m}_{\mathrm{w}}}{\rho_{\mathrm{w}}} \Delta p=\frac{0.031}{958} 19.10^{5}=60.5 \mathrm{~W}
$$

The pump work required to supply water at 21 bar is only fractionally higher at $63.7 \mathrm{~W}$.

In summary, the available energy from the exhaust flow improves by $100 \mathrm{~W}$ as the working pressure is increased from 20 to 21 bar. The pressure increase requires about $4 \mathrm{~kJ}$ of work and an increase in pump power of $3.2 \mathrm{~W}$. The energy expenditure is recovered in $42 \mathrm{~s}$.

The conclusion is reached on the assumption that there is a means of pressurizing the system. The use of the water pump in this capacity is possible, but requires a deeper analysis that will be included in a later paper. The conclusion remains that pressure change is a workable method of controlling the work output, but that the time-scales of operation need to be considered in an optimization calculation.

Stated another way, a pump could exercise control authority, but the dynamics of pressure change require a deeper insight into how pressure would be raised, and the influence of the remainder of the system on the energy requirement and response time.

\subsection{Steam dryness fraction}

The quantity of steam present in the system will vary according to the history of heat transfer and the recent discharges of steam to the expander. The purpose of the control system is to regulate both pressure and the extraction rate of steam to ensure that the system is in a state of readiness for the next phase of the duty cycle. A control function that seeks to balance the engine load (and consequently the exhaust enthalpy) with the rate of steam production will be required.

Steam entering the expander will always be at the saturation conditions corresponding to the working pressure or slightly superheated. The thermodynamic state of the accumulator will vary to suit both the operational requirements of the system and the operation of the engine. Where, for example, the demand on the engine has been consistently high, the development of steam volume may follow the following sequence of events.

1. Build the pressure and temperature of the accumulator to offer best heat transfer at the current engine conditions.

2. Draw steam off at a rate closely corresponding to the rate of heat transfer into the system - unless an unsteady form of operation would work better 
where the accumulator is run down quickly to move the engine operating point into a lower fuel consumption regime. Exhaust temperatures will tend to decrease, but by reducing pressure the heat transfer can be balanced, at the cost of a falling thermal efficiency due to the lower pressure operation.

3. As the stored thermal energy is reduced, the expander power output can be reduced in order to build up the stored energy.

\section{CONCLUSIONS AND NEXT STEPS}

Consideration of available energy in a thermal recovery system leads to the conclusion that thermal efficiencies exceeding 30 per cent can be expected. At an operating pressure of 100 bar, the maximum efficiency possible with a steady flow work-producing device is 37 per cent. In a water-based thermal recovery system, work could only reasonably be produced with heat transfer from a reservoir at the saturation temperature corresponding to the operating pressure. This is a constraint on heat exchange performance and leads to a loss of available energy. At 100 bar the corresponding maximum efficiency would be 33 per cent. In a different mode of operation, where heat is transferred incrementally to a thermal accumulator and work produced as required, the efficiency is 32 per cent at only 20 bar. The possibility of efficient operation at low pressures holds out the possibility of a low-cost and low-risk installation for passenger cars.

In the system proposed in this paper there are several controllable parameters, including independent control of the engine by means of both exhaust flowrate and temperature, as well as system pressure, pump work, and expander flowrate. The rate at which pressure can be changed depends on the physical capacity of both pump and expander. Where exhaust conditions are changing for significant periods, pressure is an effective control variable. Pressure can be changed in a time-scale of seconds, but it will take up to a minute to recover the energy through more efficient operation of the system.

The operation of the boiler brings in another variable. Large temperature differences across heat exchanger surfaces can lead to film boiling in which rates of heat transfer fall sharply. Temperature differences can be reduced through higher operating pressures, while the tendency to film boiling will be reduced if the flowrate of water through the hottest part of the boiler is increased. This can be done through a rapid use of existing steam and therefore the return flow of condensate.

Expander operation is largely dictated by its swept volume. The pressure ratio and the desired work output dictate the cut-off setting for the highpressure cylinder. If compounding is used, the cut-off setting for each of the cylinders can be employed to realize an expansion process which limits sources of irreversibility such as unconstrained expansion of steam. Nevertheless, some compromises need to be made, where pressure differences are needed to promote the flow of steam between cylinders and from the final cylinder into the condenser. Given an expansion ratio, the cut-off values can be computed in advance, and in a real-time control system they would form the basis for a best steady state value that can be used by the control system to make adjustments to meet real-time optimization requirements.

The work so far has opened up a range of possibilities that will need to be constrained through the formulation of a control strategy. The kind of trade-offs that will need to be made include:

(a) operating pressure against the rate of heat transfer;

(b) rate of steam consumption in the expander against exhaust temperature;

(c) cut-off values and the work output of the expander against the engine operating point.

An optimization process that can be used to develop the most effective operating point of both recovery system and engine will form a supervisory layer of a control system that will regulate flowrates and system temperature and pressure.

\section{ACKNOWLEDGEMENT}

The work reported in this paper has been supported by the UK Engineering and Physical Sciences Research Council (EPSRC) under Grant reference GR/T19810/01.

\section{REFERENCES}

1 Haywood, R. W. Equilibrium thermodynamics for engineers and scientists, 1980 (John Wiley \& Sons, Chichester, UK).

2 Duffy, M. C. The Still engine and railway traction. In Proceedings of the Newcomen Society, Science Museum, London, 1988.

3 Arias, D. A., Shedd, T. A., and Jester, R. K. Theoretical analysis of waste heat recovery from an 
internal combustion engine in a hybrid vehicle. Society of Automotive Engineers Annual Congress, Detroit, 2006, SAE paper 2006-01-1605.

4 El Chammas, R. E. and Clodic, D. Combined cycle for hybrid vehicles. Society of Automotive Engineers Congress, Detroit, 2005, SAE paper 2005-01-1171.

5 Bayley, F. J. The saturated liquid reservoir for energy storage in hybrid vehicles. In Proceedings of IMechE Conference on Total Vehicle Technology, September 2001, pp. 45-54.

6 Barclay, F. J. Fundamental thermodynamics of fuel cell engine and combined heat and power plant. Proc. Instn Mech. Engrs, Part A: J. Power and Energy, 2002, 216, 407-417.

7 Horlock, J. H. and Heywood, R. W. Thermodynamic availability and its applications to combined heat and power plant. Proc. Instn Mech. Engrs, Part C: J. Mechanical Engineering Science, 1986, 199(C1), 11-17.

8 Stobart, R. K. and Weerasinghe, S. R. Heat recovery and bottoming cycles for SI and CI engines - a perspective. Society of Automotive Engineers Annual Congress, Detroit, 2006, SAE paper, 2006-01-0662.

9 Fox, W. J. and McBirnie, S. C. Marine steam engines and turbines, 1970 (Newnes-Butterworths, London).

10 Vickers, P. T., Amman, C. A., Mitchell, H. R., and Cornelius, W. The design features of GM SE-101, a vapour cycle powerplant. Society of Automotive Engineers Annual Congress, Detroit, 1970, SAE paper 700163 .

\section{APPENDIX}

\section{Notation}

$a$

bkW h

$b$

$c$

$c_{p}$

$h$

$k$

$k_{q}$

$k_{T}$

$\mathrm{LCV}$ specific non-flow exergy ( $/ \mathrm{kg})$

brake (output) energy output

(kW h)

specific steady flow exergy $(\mathrm{J} / \mathrm{kg})$

intercept

specific heat capacity ( $/ \mathrm{kg} \mathrm{K}$ )

specific enthalpy $(\mathrm{J} / \mathrm{kg})$

constant

heat transfer per unit length $(\mathrm{J} / \mathrm{m})$

temperature gradient $(\mathrm{K} / \mathrm{m})$

lower calorific value $(\mathrm{J} / \mathrm{kg})$

$\begin{array}{ll}m & \text { gradient, mass }(\mathrm{kg}) \\ \dot{m} & \text { mass flowrate }(\mathrm{kg} / \mathrm{s}) \\ n & \text { polytropic index for steam } \\ & \text { compression and expansion } \\ p & \text { pressure }\left(\mathrm{N} / \mathrm{m}^{2}\right) \\ P & \text { power }(\mathrm{W}) \\ Q & \text { heat energy transfer }(\mathrm{J}) \\ s & \text { entropy }(\mathrm{J} / \mathrm{kg} \mathrm{K}) \\ T & \text { temperature }(\mathrm{K}) \\ u & \text { internal energy }(\mathrm{J}) \\ v & \text { specific volume }\left(\mathrm{m}^{3} / \mathrm{kg}\right) \\ V & \left.\text { volume (m }{ }^{3}\right) \\ W & \text { work }(\mathrm{J}) \\ x & \text { length (m) } \\ \alpha & \text { cut-off ratio } \\ \delta & \text { small increment } \\ \Delta & \text { change } \\ \Delta g & \text { specific Gibbs free energy of } \\ \Delta h & \text { reaction }(\mathrm{J} / \mathrm{kg} \mathrm{K}) \\ \eta & \text { lower calorific value of fuel }(\mathrm{J} / \mathrm{kg}) \\ & \text { rational efficiency }\end{array}$

\section{Subscripts}

boiler

c

economizer

ex

$\mathrm{H}, \mathrm{h}$

lost

L, 1

$\max$

$\min$

pump

$\mathrm{r}$

re

rev

sat

th

tot

0

$1,2,3$

gradient, mass (kg)

mass flowrate $(\mathrm{kg} / \mathrm{s})$

polytropic index for steam

compression and expansion

power (W)

heat energy transfer $(\mathrm{J})$

entropy ( $/ \mathrm{kg} \mathrm{K})$

temperature $(\mathrm{K})$

internal energy $(\mathrm{J})$

specific volume $\left(\mathrm{m}^{3} / \mathrm{kg}\right)$

volume $\left(\mathrm{m}^{3}\right)$

work (J)

cut-off ratio

small increment

change

reaction $(\mathrm{J} / \mathrm{kg} \mathrm{K})$

rational efficiency

taking place in the boiler

clearance

taking place in the economizer

exhaust

high

lost work (referring to the effect of an irreversibility)

low

maximum value

minimum value

referred to the water pump

rational (referring to efficiency)

recovered

reversible

at saturation conditions

thermal

total

at reference conditions

at intermediate stages of the

thermodynamic process 